\title{
LOS SINDICATOS Y LAS JUNTAS DE ACCIÓN COMUNAL EN COLOMBIA
}

\author{
Rocío Londoño Botero*
}

\section{INTRODUCCIÓN}

Al menos desde el punto de vista constitucional ya no se puede afirmar que el régimen político colombiano sea excluyente, centralista y autoritario. Tanto la Constitución de 1991 como las leyes y los decretos reglamentarios de la misma, otorgan una serie de derechos y herramientas a los ciudadanos en general, $\mathrm{y}$ a las comunidades indígenas y negras en particular, para organizarse autónomamente, luchar por sus intereses e incidir en la gestión pública. Además, la representación política y la iniciativa legislativa han dejado de ser patrimonio exclusivo de los partidos políticos. Sin embargo, cambiar la estructura estatal y las tradiciones sociales y políticas de más de un siglo tomará mucho más tiempo que el deseado por algunos o el imaginado en ejercicios académicos.

Aunque se advierten ciertos avances en la utilización de nuevos mecanismos institucionales para la solución de los conflictos sociales y políticos, buena parte de ellos aún ocurren al margen de la ley o por contravención de normas legales; incluso en sectores tan institucionales como las empresas y los sindicatos, más del 50 por ciento de los conflictos de los últimos cuatro años se produjeron por violación de cláusulas convencionales y normas laborales, y un poco más del 15 por ciento tuvieron como motivos la solidaridad y la protesta política, los cuales no se encuentran entre las razones admitidas legalmente para decretar una huelga ${ }^{1}$. La brecha entre la ley, los motivos y las formas más características de los conflictos sociales en Colombia no solo revela limitaciones de orden jurídico, sino también todo tipo de resistencias al acatamiento de reglas del juego relativamente estables.

A los problemas sociales y políticos estructurales del país se suman hoy los provocados por el desarrollo de la apertura económica y la adopción de políticas neoliberales en el manejo de la administración estatal y de los servicios públicos y sociales. Los principios de equidad y justicia social propios del régimen de "Democracia participativa" estatuido por la Constitución de 1991, no parecen fácilmente conciliables con los efectos sociales de la globalización de la economía y de la libertad de mercados.

En estas circunstancias conviene examinar en qué estado se encuentran las organizaciones populares y los actores sociales para responder a los complejos y paradójicos retos planteados por la transformación del régimen político, la apertura económica y la "modernización del Estado ", todo ello en un clima de deterioro social, extensión de la violencia y crisis política severa. Nuestro análisis estará centrado en la década del ochenta, pero comenzaremos con una breve descripción de la trayectoria histórica de la organización de los sectores populares, cuyo propósito no es otro que establecer las continuidades y los cambios ocurridos durante el último decenio.

\section{VISIÓN RESTROSPECTIVA}

A comienzos de este siglo el pueblo colombiano expresaba sus relaciones de solidaridad, sus aspiraciones y reivindicaciones y sus inconformidades sociales y políticas, a través de varios tipos de organización. Entre las modalidades que mayor importancia tuvieron en la vida social de entonces es preciso mencionar las siguientes: las sociedades de artesanos, las sociedades de socorro y ayuda mutua, los grupos e instituciones de caridad y beneficencia y las cooperativas de ahorro. Las mujeres ya habían comenzado a organizarse, pero sus incursiones en la vida pública se expresaban primordialmente a través de obras de caridad y beneficencia a favor de los "desvalidos de la fortuna"; aunque hubo expresiones de "género", éstas fueron bastante marginales ${ }^{2}$. La política hacía parte de la vida cotidiana de los colombianos y se expresaba primordialmente a través de la adhesión a los partidos liberal y conservador.

* Prof. Asociada. Universidad Nacional de Colombia.

1. Cfr. Alvaro Delgado, Gaviria frente al sector popular: del dicho al becho..., Revista CIEN DIAS, CINEP, Bogotá, vol. 6, N.' 26 mayo-julio, 1994. Para un conocimiento exhaustivo de las características de las huelgas y protestas sindicales en Colombia véase del mismo autor: El conflicto laboral colombiano, 1961-1990, CINEP, Bogotá, 1994, documento publicado en el IV Coloquio de Sociología. Universidad del Valle-CEREC. "Colombia al final del milenio".

2. Para una visión de las organizaciones y los movimientos sociales durante las tres primeras décadas del siglo $\mathrm{XX}$, consúltese: Torres Giraldo, Ignacio, Los inconformes, Edit. Latina, Bogotá, sin fecha, tomos 3 y 4. Urrutia, Miguel, Historia del sindicalismo en Colombia, Edit. Universidad de los Andes, Bogotá, 1969. Vásquez Toro, Magdala, Condiciona jurídica y social de la mujer, Nueva Historia de Colombia, Edit. Planeta, Bogotá, 1989, t. IV, cap. 1. 
No faltaron expresiones radicales con algún tinte socialista, pero su incidencia fue muy reducida.

La eclosión social que comienza en el decenio del veinte y se prolonga hasta finales de los años treinta, de cierta manera expresa un nuevo país: luchas agrarias, movilizaciones obreras, incursiones de los estudiantes en la política, protestas indígenas y presiones de núcleos de mujeres por cambios en la condición jurídica, social y política de su género. Sobra decir que esta época ha sido definida por los historiadores como el despegue en firme de la industrialización y la modernización del país.

Todo parece indicar que el movimiento social se desplegó en torno a dos ejes centrales: la lucha de grupos de colonos y campesinos por la tierra y por mejores condiciones de trabajo en las haciendas; y las jornadas y huelgas de los núcleos obreros por el reconocimiento legal de sus organizaciones y por reivindicaciones salariales y laborales. Las ligas agrarias, las colonias campesinas, las organizaciones de arrendatarios rurales y los sindicatos, comenzaron a desplazar a las sociedades artesanales, a las mutuarias y a las instituciones de beneficencia, sin que estas desaparecieran del todo ${ }^{3}$. En ese entonces, el surgimiento de nuevas formas de organización del campesinado y de los trabajadores urbanos se nutrió de las tradiciones de los artesanos, de las mutuarias y de los grupos cristianos, pero también tuvo tras de sí la influencia de corrientes liberales radicales, núcleos socialistas y del recién fundado partido comunista. La ocupación de haciendas, las huelgas obreras, los pliegos de peticiones, los pleitos legales y la proliferación de periódicos y panfletos, así lo atestiguan.

La violencia desatada a finales de la década del cuarenta por la confrontación liberal-conservadora, la represión oficial y conflictos locales de diverso tipo, debilitaron sensiblemente las organizaciones populares. En su lugar emergieron formas de autodefensa y resistencia que fueron transformándose en grupos armados en el campo y núcleos conspirativos en las ciudades. En este tiempo, como bien se sabe, se aceleró el ritmo de la industrialización, bajo los efectos de la segunda Guerra Mundial en la economía nacional. La violencia provocó un éxodo de gentes del campo hacia las ciudades sin precedentes en la historia nacional de suerte que el país se urbanizó abruptamente en términos del número de residentes en las ciudades, pero el impacto de este cambio en los modos de vida y la mentalidad de buena parte de los ciudadanos sería mucho más lento y difuso.

Esta fue una época de dislocamiento y de ruptura de los canales regulares y legales de expresión social y política. Las masas urbanas perdieron confianza en la Ley y en las instituciones cuando Jorge Eliécer Gaitán, su líder, fue asesinado en Bogotá el 9 de abril de 1948. Acudieron entonces al uso de la violencia y encontraron en ella una forma de expresión de su ira social y de su fuerza frente al poder de las "oligarquías". Los campesinos se vieron obligados a ocultar sus organizaciones y a utilizar las armas para defender sus tierras y sus familias. La violencia, auspiciada por el estado y los partidos legales, afectó incluso a miembros de la élite política. El movimiento sindical se sumergió en un letargo prolongado del cual sólo vendría a reponerse en la década del setenta ${ }^{4}$.
En el decenio del sesenta, con la reconciliación de los partidos "históricos" y su pacto para restablecer el orden y gobernar el país, hubo una rápida recuperación de las organizaciones populares: se reconstruyeron los sindicatos liberales y comunistas; el sindicalismo católico, que había emergido durante la violencia con el auspicio de la iglesia católica y los gobiernos conservadores, desplegó una actividad inusitada. Entre 1965 y 1980 el sindicalismo logró la tasa de afiliación más alta en su historia, pero ésta no sobrepasó el 16 por ciento de la población ocupada del país. También reaparecieron las luchas agrarias bajo sus formas antiguas, pero entrelazadas con la guerrilla, y se produjo una nueva ola de luchas por la tierra.

Los efectos de la urbanización y la industrialización del país se dejaron sentir en la irrupción de nuevos sectores medios. Los estudiantes participaron activamente en el derrocamiento del gobierno militar de Rojas Pinilla en 1957, presionaron reformas en la educación y se convirtieron en un canal importante de la inconformidad política con el Frente Nacional. Los empleados de "cuello blanco" del Estado, junto con médicos, maestros y jueces, se asociaron en sindicatos y asumieron formas de protesta propias de los obreros. Aumentaron los grupos de mujeres y sus actividad se fue haciendo cada vez más política y más de género; el gobierno militar de Rojas Pinilla había reconocido nominalmente el voto femenino y durante el Frente Nacional las mujeres lograrían ciertas conquistas como el Estatuto de Igualdad jurídica de los sexos y la celebración del año internacional de la mujer ${ }^{5}$. La irrupción de sectores medios también tuvo expresiones en movimientos culturales e intelectuales y en un relativo auge de las expresiones políticas de izquierda.

El surgimiento del movimiento de los "Destechados" en Cali, encabezado por el líder liberal Alfonso Barberena y el comunista Julio Rincón, constituyó una de las expresiones primordiales de los campesinos urbanizados a la fuerza. Los altos índices de la migración rural generaron nuevas necesidades de vivienda y servicios públicos en las ciudades, como también de mecanismos de integración social. Sin embargo, ante la carencia de soluciones estatales, muchos migrantes se vieron obligados a acudir a la invasión de lotes ociosos y a la creación de asentamientos espontáneos y clandestinos. Por lo demás, como lo han señalado diversos investigadores, durante este tiempo se desplegaron en el país diversas formas de protesta urbana, entre las cuales se destacarían los paros y movimientos cívicos ${ }^{6}$.

3. Cfr. Archila, Mauricio, Cultura e identidad obrera, Colombia 1910-1945, CINEP, Bogotá, 1991

4. Cfr. Sánchez, Gonzalo y Peñaranda, Ricardo, compiladores, Pasado y presente de la violencia en colombia, CEREC, Bogotá, 1986. Guzmán Campos y otros, La violencia en Colombia, Carlos Valencia Editores, Bogotá, 1986.

5. Cfr. Lluna, Lola y Villarreal, Norma. Historia, genero y política. movimientos de mujeres y participación política en Colombia 1930-1991. Editado por el seminario Interdisciplinar Mujeres y Sociedad, Universidad de Barcelona, y la Comisión Interministerial de Ciencia y Tecnología, Barcelona, 1994.

6. Véase entre otros: Medófilo Medina, La protesta urbana en Colombia, Ediciones Aurora, Bogotá, 1984. Torres Carrillo, Alfonso, La ciudad en la sombra, CINEP, Bogotá, 1993. 
El movimiento sindical acudió a formas de protesta y presión más radicales, entre las cuales se destacaron la "toma de fábricas" y los ensayos de paro general. "En esta coyuntura, las huelgas tuvieron una magnitud sin precedentes: entre 1962 y 1973 ocurrieron 697 huelgas y 5 intentos de paro nacional..." Pero la toma de fábricas no pasó de ser una modalidad de protesta efímera y la huelga general sólo en contadas ocasiones fue relativamente exitosa?

Los gobiernos del Frente Nacional diseñaron y ensayaron varias formas y mecanismos para atenuar los efectos sociales y políticos de la "Violencia" y para canalizar las reivindicaciones y los conflictos sociales. Desde 1958, con la administración del presidente Alberto Lleras Camargo, comenzó la construcción del andamiaje de la Acción Comunal en las veredas rurales y en los barrios marginados de las ciudades; una década después, por iniciativa del presidente Carlos Lleras Restrepo, se fundó la Asociación Nacional de Usuarios Campesinos, ANUC. A comienzos de los años setenta, en relación muy estrecha con las actividades desplegadas por la ANUC, resurgió el movimiento indígena bajo la dirección del Consejo Regional Indígena del Cauca, CRIC.

En este breve e incompleto recuento histórico se advierte que, con excepción de los sindicatos, la mayor parte de los grupos y las organizaciones sociales existentes emergieron en la década del sesenta y comienzos del setenta. En los últimos años las experiencias sociales más novedosas han sido la organización de las comunidades negras, la creación de la Organización Nacional Indígena de Colombia ONIC, la Asociación Nacional de Usuarios del DRI, ANDRI, los grupos ecológicos y los comités y grupos de solidaridad y defensa de los derechos humanos. Aunque la gama de organizaciones sociales hoy día es bastante amplia y diversa, su proceso de afianzamiento ha sido lento y difícil, no sólo por la resistencia de la clase dominante y de los gobiernos a aceptar interlocutores sociales autónomos, sino también por la violencia recurrente que ha padecido el país y la poca disposición que han mostrado la mayoría de los líderes sociales a colocarse a tono con los nuevos tiempos.

\section{LAS ORGANIZACIONES CONTEMPORÁNEAS}

El vertiginoso ritmo de las construcciones y de las demoliciones en las ciudades produce la sensación de que Colombia es un país joven, dinámico y moderno. Algo similar podría afirmarse de la incesante promulgación de leyes, decretos y programas sociales, como también del olvido de la historia y del pasado más reciente por parte de los gobernantes y funcionarios de turno. Colombia no es una sociedad "post-moderna", pero padece fascinación por lo "nuevo". Sin embargo, las innovaciones físicas y legislativas parecen transcurrir sin afectar sensiblemente las condiciones de vida, el comportamiento y las costumbres de buena parte de los colombianos. En los barrios populares, antiguos y nuevos, persisten costumbres domésticas y colectivas de raigambre rural. La familia, según Carlos Lemoine $^{8}$, sigue teniendo una enorme importancia no sólo en términos afectivos y en los procesos de socialización, sino también como unidad de apoyo para la subsistencia diaria. Casi todos los colombianos creen en Dios y la Iglesia Católica es la institución que les inspira mayor confianza. Una imagen pública que algo revela del país actual es la del candidato liberal Ernesto Samper, hoy presidente en ejercicio, encomendándose al popular "Niño Jesús" del barrio 20 de Julio.

Los índices de deterioro de las relaciones de convivencia y el uso frecuente de la violencia para dirimir querellas privadas y conflictos sociales, no se compadece con la incesante promulgación de medidas que buscan pacificar el país y estimular el diálogo y la concertación. La disociación entre las normas y las costumbres sociales y políticas aparece como uno de los rasgos singulares del comportamiento individual y colectivo de los colombianos, incluyendo en él a líderes y funcionarios públicos y privados. Aunque se tiene conciencia de sus efectos negativos en la convivencia y la disciplina social, parece aceptárselo como algo intrínseco al "modo de ser" de los colombianos.

Las ocupaciones informales mantienen un elevado peso en la estructura laboral y son muchos los colombianos que trabajan en condiciones precarias. En Colombia, según Hugo López, el 54,8 por ciento del empleo urbano está localizado en unidades económicas que ocupan menos de 10 trabajadores ${ }^{9}$, muchas de las cuales no cumplen normas laborales tan básicas como el pago del salario mínimo legal y las prestaciones sociales, la afiliación a algún sistema de seguridad social y la remuneración especial de horas extras, entre otras.

El índice de Necesidades Básicas Insatisfechas (NBI) muestra que más del 40 por ciento de los colombianos vive en condiciones de pobreza. Además del "rebusque" diario para la subsistencia, los habitantes pobres de las ciudades se ven abocados a solucionar sus necesidades de vivienda habitando en inquilinatos infrahumanos y mediante sistemas de autoconstrucción precarios e ilegales. Según INUR$\mathrm{BE}$, "aproximadamente el 40 por ciento de las nuevas viviendas producidas en los últimos 20 años, se han hecho por fuera de las normas de planificación urbana y de la capacidad local de proveerlas de servicios básicos" ${ }^{10}$. Las estadísticas del CENAC indican que en 1994 la demanda insatisfecha de vivienda superaba los dos millones de unidades y que en las diez principales ciudades cerca de 2.300.000 hogares padecen problemas tales como hacinamiento y carencia de servicios públicos ${ }^{11}$.

7. Para una visión sintética de este período del movimiento sindical Véase Londoño, Rocío, Crisis y recomposición del sindicalismo colom biano (1946-1980), Nueva Historia de Colombia, Edit. Planeta, Bogotá, 1989, t. III, cap. 11.

8. Lemoine, Carlos, Las fuerzas de la opinión, Centro Nacional de Consultoría, Bogotá, 1993.

9. López, Hugo, Contexto macroeconómico colombiano, mercado laboral urbano y retos para una politica de empleo, FESCOL, Documento inédito, Medellín, 1993.

10. Inurbe, La revolución pacifica, politica nacional de vivienda, República de Colombia, Presidencia de la República, Ministerio de Desarrollo Económico, Bogotá, 1992.

11. Cfr. Sarmiento, Libardo, Reformas y desarrollo social en los noventa, en Francisco Leal Buitrago (compilador), En busca de la estabilidad perdida, Tercer Mundo-IEPRI-Colciencias, Bogotá, 1995, pg. 318 Ministerio de Desarrollo Económico, Ciudades y Ciudadania, La política urbana del Salto Social, Bogotá, 1995, pgs. 146 y 147. 
El decrecimiento de la población rural, cuyo ritmo aumentó en el último decenio, antes que por procesos de modernización y tecnificación de las actividades agropecuarias, sigue siendo provocado por fenómenos tales como la agudización de la violencia, los bajos salarios, la escasa inversión estatal en obras de infraestructura y la carencia de estímulos económicos y sociales para el campesinado.

Aunque la cobertura de la educación ha aumentado, persisten bajos niveles educativos en amplias franjas de la población y la calidad de los programas de enseñanza deja mucho que desear. El censo de 1993 indica que cerca de la mitad de la población colombiana solamente tiene educación primaria, menos de la tercera parte cursó estudios secundarios y una pequeña franja, que no llega a la décima parte, hizo estudios universitarios.

Esta somera enumeración de carencias padecidas por una proporción considerable de colombianos no tiene otro propósito que llamar la atención sobre ciertos problemas estructurales que han incidido de manera notable en el bajo grado de organización de los sectores populares y en algunas de las características de sus formas de asociación.

\section{TIPOS Y GRADOS DE ORGANIZACIÓN}

Tanto en las ciudades como en el campo, la unidad familiar, la pequeña comunidad de vecinos y los grupos primarios siguen teniendo un peso importante en la vida social, pero han dejado de ser suficientes para la socialización y la lucha diaria por la subsistencia. Los trabajadores asalariados y los pobres en general se han visto abocados a asociarse de diversas formas para solucionar sus necesidades básicas y para tratar de satisfacer las aspiraciones que les genera la vida moderna. La variedad de formas de asociación parece responder principalmente a las necesidades de subsistencia de una buena parte de la población y en menor medida a nuevas expresiones de la sociedad civil. Es así como el espectro actual de la organización social abarca desde las mutualidades e instituciones de caridad, cuyo origen data del siglo pasado, hasta grupos ecológicos de muy reciente fundación. Sin embargo, los problemas y las reivindicaciones alrededor del trabajo y del hábitat continúan siendo los ejes centrales de la movilización popular. Las asociaciones constituidas en torno a reivindicaciones y afinidades de género, culturales, étnicas, ecológicas, generacionales... etcétera, han venido cobrando fuerza, pero aún están lejos de alcanzar la influencia de las más tradicionales.

En términos de cobertura territorial y número de afiliados, las modalidades de asociación más expandidas y con mayor peso en la movilización social son las juntas de Acción Comunal y los sindicatos. Aunque la Acción Comunal surgió varias décadas después de la organización sindical, hoy día está mucho más extendida que aquella. En 1993 fueron registradas 42.582 juntas de Acción Comunal y cerca de 2.500 .000 afiliados en el país (cuadro I), cifra que equivale al 11 por ciento de la población comprendida entre los 18 y 64 años de edad. El volumen de afiliados a la Acción Comunal en la áreas urbanas supera ligeramente el
CUADRO I

JUNTAS DE ACCIÓN: NÚMERO DE AFILIADOS Y DISTRIBUCIÓN PORCENTUAL POR DEPARTAMENTOS

\begin{tabular}{|l|r|r|}
\hline Departamento & $\begin{array}{c}\text { Afiliados } \\
\text { Comunales }\end{array}$ & $\begin{array}{c}\text { Participación } \\
\text { Porcentual } \\
\text { Total Nacional }\end{array}$ \\
\hline Amazonas & 2,536 & $0,10 \%$ \\
Antioquía & 136,499 & $5.52 \%$ \\
Arauca & 13,257 & $0.54 \%$ \\
Atlántico & 25,826 & $1.04 \%$ \\
Bolívar & 93,960 & $3.80 \%$ \\
Boyacá & 117,018 & $4.73 \%$ \\
Caldas & 51,000 & $2.06 \%$ \\
Caquetá & 44,176 & $1.79 \%$ \\
Casanare & 26,228 & $1.06 \%$ \\
Cauca & 152,677 & $6.17 \%$ \\
César & 74,054 & $2.99 \%$ \\
Córdoba & 68,100 & $2.75 \%$ \\
Cundinamarca & 180,396 & $7.29 \%$ \\
Choco & $\mathrm{S} . \mathrm{I}$. & \\
Guainía & 1,376 & $0.06 \%$ \\
Guajira & 19,741 & $0.80 \%$ \\
Guaviare & 6,444 & $0.26 \%$ \\
Huila & 81,965 & $3.31 \%$ \\
Magdalena & 50,037 & $2.02 \%$ \\
Meta & 51,912 & $2.10 \%$ \\
Nariño & 61,931 & $2.50 \%$ \\
Nte. de Santander & 132,805 & $5.37 \%$ \\
Putumayo & 41,962 & $1.70 \%$ \\
Quindio & 28,636 & $1.16 \%$ \\
Risaralda & 54,052 & $2.19 \%$ \\
San Andrés & 1,966 & $0.08 \%$ \\
Santafé de Bogotá & 327,977 & $13 \%$ \\
Santander & 176,700 & $0.97 \%$ \\
Sucre & 24,000 & $7.61 \%$ \\
Tolima & 226,000 & $0.30 \%$ \\
Valle & 188,192 & $0.17 \%$ \\
Vaupés & 7,435 & $100.00 \%$ \\
Vuchada & 4,169 & \\
\hline TOTALES & $2,473,027$ & \\
\hline
\end{tabular}

Fuente: Censo Nacional Calificado de Juntas Acción Comunal, 1993. Ministerio de Gobierno, Dirección General de Integración y Desarrollo de la Comunidad, Bogotá, 1993, pgs. 15 y 16.

número total de sindicalizados en el país ${ }^{12}$. Según los datos del último censo sindical ${ }^{13}$, en 1990 existían 2.265 sindicatos con cerca de 900.000 afiliados, cifra que corresponde aproximadamente a un 8 por ciento de la población ocupada del país. Aunque hay sindicatos en todo el territorio nacional, un poco más de la mitad de los trabajadores sindicalizados está concentrado en los departamentos de Cundinamarca, Antioquía y Valle y en sus respectivas capitales (cuadro II). Tanto la Acción Comunal como los sindicatos congregan habitantes y trabajadores de las ciudades y del campo, pero la distribución de sus afiliados es un tanto diferente: las juntas comunales tienen mayor peso en las zonas rurales ( 70 por ciento de las juntas y el 53 por ciento de los afiliados son rurales) en tanto que el sindicalismo es predominantemente urbano (90 por ciento de los sindicatos y el 95 por ciento de los afiliados están en las ciudades).

Por razones obvias el espectro organizativo de la población rural es menos diverso que el de la población urbana. Entre las formas específicas de organización rural se encuentran la Asociación Nacional de Usuarios Cam-

12. Ministerio de Gobierno, DIGIDEC, Censo nacional calificado de juntas de acción comunal 1993, Santafé de Bogotá, noviembre de 1993.

13. Ministerio de Trabajo y Seguridad Social, III Censo Nacional Sindical, en Boletín de Análisis y Estadísticas Laborales, Bogotá, juliodiciembre, 1989, N. ${ }^{\circ} 41$, pgs. 32-49. Aunque el Boletín aparece fechado en 1989, el censo fue realizado entre agosto de 1989 y mayo de 1990 de suerte que los resultados estadísticos en realidad fueron publicados en 1990 y aparecen registrados con esta fecha. 
CUADRO II

\begin{tabular}{|c|c|c|c|c|c|c|}
\hline \multirow[b]{2}{*}{$\begin{array}{l}\text { SECCIÓN } \\
\text { DEL PAIS }\end{array}$} & \multicolumn{2}{|c|}{ 1947-1984 } & \multicolumn{2}{|c|}{ 1984-1990 } & \multicolumn{2}{|c|}{$1947-1990$} \\
\hline & $\begin{array}{l}\text { Crecimiento } \\
\mathrm{N} \cdot{ }^{\circ} \text { Sindicatos }\end{array}$ & $\begin{array}{l}\text { Crecimiento } \\
\text { Población } \\
\text { Afliada }\end{array}$ & $\begin{array}{c}\text { Crecimiento } \\
\text { N.'Sindicatos }\end{array}$ & $\begin{array}{c}\text { Grecimiento } \\
\text { Población } \\
\text { Afliada }\end{array}$ & $\begin{array}{c}\text { Crecimiento } \\
\text { N. Sindicatos }\end{array}$ & $\begin{array}{c}\text { Creeimiento } \\
\text { Poblsáón } \\
\text { Afliliada }\end{array}$ \\
\hline Antioquía & $160 \%$ & $488 \%$ & $6 \%$ & $.0 .4 \%$ & $174 \%$ & $485 \%$ \\
\hline Atlántico & $55 \%$ & $65 \%$ & $15 \%$ & $28.2 \%$ & $78 \%$ & $112 \%$ \\
\hline Bogotá & $230 \%$ & $577 \%$ & $.9 \%$ & $-20.7 \%$ & $202 \%$ & $437 \%$ \\
\hline Bolivar & $25 \%$ & $158 \%$ & $6 \%$ & $26.4 \%$ & $33 \%$ & $227 \%$ \\
\hline Boyacá & $26 \%$ & $278 \%$ & $.33 \%$ & $24.6 \%$ & $.15 \%$ & $370 \%$ \\
\hline Caldas & $6 \%$ & $226 \%$ & $-4 \%$ & $25 \%$ & $1 \%$ & $234 \%$ \\
\hline Caquetá & & & $9 \%$ & $-0.9 \%$ & & \\
\hline Cauca & $163 \%$ & $620 \%$ & $55 \%$ & $50.2 \%$ & $306 \%$ & $982 \%$ \\
\hline Cesar & & & $0 \%$ & $39.0 \%$ & & \\
\hline Córdoba & & & $.11 \%$ & $6.3 \%$ & & \\
\hline Cundinamarca & $-40 \%$ & $-30 \%$ & $71 \%$ & $199.9 \%$ & $2 \%$ & $110 \%$ \\
\hline Chocó & $25 \%$ & $215 \%$ & $.27 \%$ & $38.0 \%$ & $.8 \%$ & $335 \%$ \\
\hline Guajira & $0 \%$ & & $28 \%$ & $53.0 \%$ & & \\
\hline Huila & $488 \%$ & $1048 \%$ & $0 \%$ & $.8 .0 \%$ & $488 \%$ & $956 \%$ \\
\hline Magdalena & $86 \%$ & $395 \%$ & $12 \%$ & $10.1 \%$ & $107 \%$ & $445 \%$ \\
\hline Meta & $3400 \%$ & $66531 \%$ & $29 \%$ & $-45.0 \%$ & $4400 \%$ & $36526 \%$ \\
\hline Nariño & $221 \%$ & $238 \%$ & $33 \%$ & $9.0 \%$ & $328 \%$ & $268 \%$ \\
\hline Norte de Santender & $104 \%$ & $504 \%$ & $51 \%$ & $-11.3 \%$ & $208 \%$ & $436 \%$ \\
\hline Quindio & & & $.19 \%$ & $-14.5 \%$ & & \\
\hline Risaralda & & & $4 \%$ & $39.6 \%$ & & \\
\hline Santander & $144 \%$ & $311 \%$ & $2 \%$ & $15.5 \%$ & $149 \%$ & $375 \%$ \\
\hline Sucre & & & $9 \%$ & $24.9 \%$ & & \\
\hline Tolima & $65 \%$ & $626 \%$ & $.7 \%$ & $-17.0 \%$ & $53 \%$ & $503 \%$ \\
\hline Valle & $113 \%$ & $445 \%$ & $1 \%$ & $5.2 \%$ & $114 \%$ & $473 \%$ \\
\hline Territorios Nal. & $2800 \%$ & $13045 \%$ & $17 \%$ & $100.6 \%$ & $3300 \%$ & $26225 \%$ \\
\hline TOTAL NAL. & $143 \%$ & $429 \%$ & $4 \%$ & $0.8 \%$ & $154 \%$ & $433 \%$ \\
\hline
\end{tabular}

pesinos, ANUC, creada en 1970 y la Asociación Nacional de Usuarios DRI, ANDRI, en 1985. En el ámbito rural también hay que incluir a las organizaciones de indígenas y campesinos negros y a una serie de grupos locales que, según León Zamocs, han sido propiciados por grupos políticos como la Unión Patriótica, A Luchar, el Frente Popular y por los grupos guerrilleros ${ }^{14}$.

Sobre la magnitud de la organización rural es posible decir lo siguiente: la Acción Comunal contaba en 1993 con 1.329.704 afiliados y 29.807 juntas locales en el campo. En el sector agropecuario existían 233 sindicatos con 48.900 afiliados en 1990. A la ANDRI pertenecían 80.000 afiliados en 1990, distribuidos en 18 juntas departamentales, 320 juntas municipales (213 activas) y 2.500 juntas veredales "relativamente activas". Sobre el número de afiliados a la ANUC oficial y la ANUC-UR no hay información disponible; en los documentos del Congreso de Unidad y Reconstrucción de ANUC, celebrado en 1987, no se menciona un solo dato de este orden y nos fue imposible obtener información por parte de los directivos que operan en Bogotá. En resumen, si se exceptuan las dos ANUC, las organizaciones indígenas y negras y los grupos locales informales, la población rural organizada en juntas comunales, sindicatos y en la ANDRI ascendería a 1.458.000 personas aproximadamente.

Un hecho relativamente reciente es el peso que en la Acción Comunal y los sindicatos han adquirido las mujeres. Con base en los censos consultados puede afirmarse que hoy día ellas son cerca del 34 por ciento de los afiliados a los sindicatos y 41,6 por ciento de los miembros de la Acción Comunal, lo cual significa un número aproximado de 1.175.000 mujeres. El peso numérico de las mujeres en estas organizaciones ha conllevado, entre otras cosas, cierto reconocimiento de sus reivindicaciones y preocupaciones, pero su representación en los aparatos directivos es aún muy reducida.

Los problemas y las reivindicaciones relacionados con la vivienda han sido asumidos por una gama diversa de organizaciones. Según el tipo de afiliados, los objetivos y las formas de acción, es posible clasificar estas organizaciones en tres grandes modalidades. En primer lugar, las asociaciones de adjudicatarios de planes oficiales, inquilinos y habitantes de barrios "piratas", subnormales y normalizados. En segundo lugar, las cooperativas de Vivienda, Ahorro y Crédito y otras formas asociativas, las cuales desarrollan planes de construcción y mejoramiento de vivienda y cuentan con sistemas de crédito para sectores con cierta capacidad de pago. En tercer lugar, las fundaciones y ONG's orientadas principalmente hacia la asistencia legal y técnica y el diseño de programas de vivienda.

No existe información precisa y confiable sobre el número y tamaño de estas organizaciones. El censo de organizaciones sociales elaborado por el Instituto Sindical María Cano, ISMAC, registra 400 organizaciones locales y regionales de vivienda y un número global de 700.000 afiliados $^{15}$. Sin embargo, debido a la escasa confiabilidad de estos datos, es preferible atenerse a una evaluación cualitativa hecha por un equipo de Foro Nacional por Colombia INURBE ${ }^{16}$. En esa evaluación se afirma que en los últimos años se produjo cierto afianzamiento de las organizaciones de vivienda popular, entre las cuales se destacan las siguientes: CENAPROV (1959), FEDEVIVIENDA (1982), CONSTRUYAMOS (1983), CEMPAVI (1986) y FENAVIP (1992). Por las fechas de fundación de estas organizaciones, colocadas entre paréntesis, se advierte que su trayectoria es bastante corta con excepción de CENAPROV.

En la década del 80 las asociaciones de vivienda popular intentaron generar un nuevo "Movimiento de Viviendistas"; para tal fin realizaron el "Primer Congreso Unitario de Organizaciones Populares de Vivienda", en agosto de 1985 en Bogotá. En ese evento se constituyó una coordinadora nacional de organizaciones de vivienda popular que posteriormente dio lugar al actual Consejo Nacional de Vivienda Popular, CONAVIP.

La fundación de grupos ecológicos es un fenómeno típico de la década del ochenta, sin mayores antecedentes en Colombia. Organizaciones como el Colegio Verde de Villa de Leyva y las fundaciones NATURA y GAVIOTAS, entre otras, han llevado a cabo la formación de grupos ecológicos, investigaciones sobre variados problemas ambientales y han diseñado proyectos de "uso sustentable de recursos naturales" con comunidades campesinas e indígenas. Su incidencia en las campañas de educación para la preservación y la explotación adecuada de los recursos naturales y del patrimonio ambiental ha sido notable.

14. Para una visión de la organización en el último decenio Zamosc León, El campesinado y las perspectivas para la democracia rural, "Al filo del Caos", Tercer Mundo-Instituto de estudios Políticos y Relaciones Internacionales, Bogotá, 1990, tercera parte, cap. 1. Censo sindical 1990, Op. Cit., Censo Juntas de Acción Comunal, Op. Cit. ANDRI, El surgimiento de la Andri en el proceso de las luchas campesinas, mimeo, Bogotá, sin fecha. Universidad del Valle-Universidad de los Andes, Proyecto de desarrollo de una metodología de evaluación de impacto y levantamiento de linea de base del programa de desarrollo integral campesino, PDIC, Informe final, Bogotá agosto de 1992. ANUC, Ponencias y conclusiones del congreso de unidad y reconstrucción de ANUC, Bogotá, agosto 26-28, 1987.

15. Instituto María Cano, ISMAC, Las organizaciones sociales y la Constituyente, Bogotá, julio 1990, carpeta técnica N. ${ }^{\circ}$ 5, pgs. 1-2.

16. Foro Nacional por Colombia-Inurbe, Evaluación de organizaciones de vivienda popular en Santafé de Bogotá, Santafé de Bogotá, diciembre 1993, documento inédito. 
Si se tiene en cuenta la corta trayectoria de las organizaciones ecológicas, resulta sorprendente su proceso de aglutinación nacional alrededor de la corporación ECOFONDO, creada en 1993. En el breve lapso de un año se afiliaron a esta entidad cerca de 400 organizaciones de casi todas las regiones del país. También se destaca la constitución de los cabildos verdes en los municipios, cuyo avance más notable se advierte en el departamento de Boyacá ${ }^{17}$. En el rápido incremento de los grupos ecológicos seguramente han incidido varios factores: recursos y campañas de carácter internacional, mayor conciencia en algunos ciudadanos de la incidencia de los ecosistemas en el bienestar material y social y cierto apoyo oficial. Tampoco ha faltado el entusiasmo con la novedad y la moda de este tema en el país.

No podríamos concluir esta somera descripción de las modalidades de organización popular en Colombia sin mencionar los grupos de solidaridad con las víctimas de la violencia y la defensa de los derechos humanos. La primera organización creada con estos propósitos fue el Comité Permanente por la Defensa de los Derechos Humanos, cuya fundación en 1979 contó con el auspicio de diversas asociaciones gremiales y políticas. Además de este Comité, las organizaciones más destacadas por sus actividades de investigación y educación en los asuntos relacionados con los derechos humanos y en las denuncias sobre violaciones de los mismos, han sido, entre otras, las siguientes: Cinep, Comisión Andina de Juristas, Credhos, País Libre, Asfades y el Comité de Solidaridad con los presos políticos. La importancia que ha cobrado el tema de los derechos humanos también se advierte en la creación de más de un centenar de grupos y comités en diferentes regiones y municipios del país ${ }^{18}$ y en el hecho de que comienza a ser reconocido como uno de los asuntos públicos importantes.

Con base en los censos citados y en estimaciones indirectas podría afirmarse que por lo menos cuatro millones y medio de colombianos pertenecen a alguna de las organizaciones formales constituidas en torno a reivindicaciones colectivas de carácter laboral y social. El hecho de que cerca del 20 por ciento de los colombianos, entre los 18 y los 64 años, esté vinculado a alguna organización social estable, constituye un potencial social apreciable. Este potencial podrá valorarse mejor si se tienen en cuenta, de una parte los problemas sociales, legales y políticos que han restringido las posibilidades de organización y, de otra, la infinidad de grupos informales cuya incidencia en la dinámica social está aún por estudiarse.

\section{LA ACCIÓN COMUNAL}

Mientras que el reconocimiento legal y político de los sindicatos ha sido objeto de una prolongada y dura lucha de los trabajadores, la Acción Comunal nació como iniciativa estatal durante la administración del presidente Alberto Lleras Camargo, y contó desde el comienzo con el auspicio institucional requerido para su implantación en el conjunto del territorio nacional. El diseño de esta organización estuvo inspirado en políticas internacionales de la
"Alianza para el Progreso", orientadas a resolver problemas críticos relacionados con la pobreza y a prevenir y atenuar los conflictos generados por las carencias y aspiraciones de amplios sectores sociales. Estas políticas fueron experimentadas en Estados Unidos a finales de los cuarenta, como parte de lo que Daniel Bell denomina "la revolución comunitaria", cuyos puntos centrales fueron la "guerra a la pobreza" y la "ideología de la participación", cuyo lema central era: "ayudar a los individuos para que se ayuden a sí mismos". El corazón de la "revolución comunitaria" en Estados Unidos fueron los barrios pobres de la ciudad de New York, en los cuales a duras penas se logró la participación de un 10 por ciento de la población a la cual el Estado pretendía ayudar para que se ayudara a sí misma ${ }^{19}$.

En el caso colombiano este tipo de programas fueron aplicados inicialmente en los epicentros de la "Violencia" y se fueron extendiendo paulatinamente a otras zonas rurales y a los barrios "marginados" de las grandes ciudades. Uno de los programas propuestos por la Comisión Nacional de Rehabilitación, creada en 1958, fue la Acción Comunal, programa que también sería recomendado por el equipo académico que realizó el primer estudio sobre la "Violencia" ${ }^{20}$. La política estatal de promoción de la Acción Comunal fue sancionada mediante la expedición de la Ley 19 de 1958; un año después el gobierno expidió el decreto reglamentario 1761/59 que dispuso, entre otras medidas, la creación de la División de Acción Comunal en el Ministerio de Educación; al año siguiente esta División fue trasladada al Ministerio de Gobierno en donde funcionó hasta 1968, cuando fue creada la Dirección de Integración y Desarrollo de la Comunidad, DIGIDEC. Posteriormente las funciones de esta División fueron ampliadas en la Ley 52 de 1990 y el Decreto 646 de abril 14 de 1992, que creó los Consejos de Integración y Desarrollo de la Comunidad.

De conformidad con los propósitos iniciales del programa, a comienzos de la década del sesenta la creación de las juntas de la Acción Comunal estuvo focalizada en las zonas rurales de los departamentos de Caldas, Huila, Santanderes, Tolima, Valle y $\mathrm{Nariñno}^{21}$. En el curso de más de tres décadas la organización comunal se extendió al conjunto del territorio nacional de suerte que hoy congrega más de dos millones y medio de afiliados, distribuidos en los 32 departamentos y el Distrito Capital de Santafé de

17. Para una visión relativamente amplia de la organización y los programas de las fundaciones y corporaciones ecológicas pueden consultarse los siguientes documentos: Ecofondo, Materiales de trabajo 1 y 2, Boletín Año 2, Santafé de Bogotá, febrero-marzo, 1994. Fundación Natura, Informe Anual 1992, Santafé de Bogotá, 1992. Colegio Verde de Villa de Leyva, Cuadernos verdes, Nos. 1-8, Santafé de Bogotá; Corporación el colegio Verde de Villa de Leyva, sin fecha.

18. Un listado de grupos locales de Derechos Humanos se encuentra en Potes, Israel, Directorio Colombia 1994, Organizaciones sindicales campesinas, Derechos Humanos, Educación e Investigación, Medios de Comunicación, Santafé de Bogotá, marzo 1994.

19. Cfr. Bell, Daniel \& Held, Virginia. The comunity revolution. En Cities in change, studies on the urban condition. John Walton and Donald E. Carns, Boston: Allyn and Bacon, Inc. Boston, 1973, Chapter IV.

20. Cfr. La violencia en Colombia, Op. Cit. vol. 2.

21. Cfr. Cantillo José María. Vinculación de la organización comunitaria al desarrollo. Escuela Superior de Administración Pública, Bogotá 1988, Cuadernos ESAP N. ${ }^{\circ} 15$. 
Bogotá (cuadro 1). Entre los posibles indicadores de la representatividad de la Acción Comunal cabe mencionar los más básicos: en 1993 el número de sus afiliados correspondía al 11 por ciento de la población entre los 18 y 64 años de edad y al 17 por ciento de los colombianos registrados en el censo electoral.

En la composición actual de la Acción Comunal aún predominan las juntas y los afiliados de las zonas rurales, que representan el 70 por ciento y el 53 por ciento de las cifras respectivas a nivel nacional. El número de juntas urbanas es bastante menor, pero el porcentaje de afiliados en las ciudades asciende al 47 por ciento del total. Las cifras históricas muestran un crecimiento continuo de esta organización, pero una observación más atenta de las mismas revela que su ritmo ha ido disminuyendo: mientras que en la década del sesenta de crearon un promedio de 1610 juntas por año, en las décadas del setenta y del ochenta el crecimiento anual descendió a 1400 y 1257 respectivamente.

A pesar del descenso en su ritmo de crecimiento, es indudable que la Acción Comunal es hoy día la organización más estable en el ámbito rural y ha adquirido un peso considerable en los barrios populares. La constatación de este hecho exige una interpretación distinta de aquella, tan común en los analistas y algunos dirigentes de los movimientos sociales, que sólo ha visto a las juntas comunales como aparato de control estatal y de reproducción del clientelismo bipartidista. A continuación se exponen algunas consideraciones sobre la perdurabilidad de la Acción Comunal y su peso en la estructura social.

En primer lugar, su doble carácter de asociación comunitaria e institucional, facilitó la reconstitución de una parte importante de las comunidades rurales que habían sido desvertebradas durante la "Violencia". La adopción de la vereda comunidad de base de la organización rural permitió una relación más directa entre las demandas específicas de los habitantes del campo y los recursos y programas provenientes del Estado. En este sentido, las juntas comunales se convirtieron en un intermediario relativamente eficaz entre las comunidades rurales y el Estado ${ }^{22}$.

En segundo lugar, la composición bipartidista que tuvieron las juntas comunales durante el Frente Nacional, influyó de manera contradictoria en la incorporación social y política de las comunidades rurales y los barrios populares. Por una parte, facilitó la reintegración de comunidades de las zonas de "Violencia" y la canalización de recursos estatales para tal fin; pero, por otra, marginó a grupos campesinos y urbanos que militaban en organizaciones y movimientos distintos o contrarios al Frente Nacional. Por lo demás, el obligado carácter bipartidista de los organismos directivos ciertamente los hizo proclives al clientelismo y excluyentes, al tiempo que simuló nexos de subordinación de los líderes comunales con los jefes políticos locales y regionales.

En tercer lugar, la estabilidad y el arraigo social que habían logrado las juntas comunales impidió su desvertebración durante el desmonte del Frente Nacional. La imbricación de la Acción Comunal en la vida cotidiana de las comunidades rurales y urbanas es explicable, entre otras razones, por su relativa eficacia en la construcción de obras de infraestructura y servicios comunitarios, el fomento de actividades sociales, deportivas y recreativas y, más recientemente, la labor de conciliación en casos de conflictos vecinales. En algunos estudios también se ha subrayado el hecho de que las juntas comunales han sido el principal soporte de programas oficiales como el de Desarrollo Rural Integrado (DRI) y el Plan Nacional de Rehabilitación (PNR), antes de que los usuarios de estos programas crearan sus propias asociaciones.

Aunque las juntas comunales han padecido serios problemas de rutinización y clientelismo y, en no pocos casos, se han quedado en labores elementales de "arena y pala", la participación de nuevos sectores en sus organismos de dirección y la influencia de los movimientos cívicos en las luchas locales, han contribuido a su revitalización y su vinculación con otra organizaciones populares. No es del todo cierto, como se ha dicho en algunas publicaciones, que los movimientos cívicos se hayan desarrollado de manera espontánea o al margen de las organizaciones existentes; en el bien documentado estudio de Luz Amparo Fonseca sobre estos movimientos, se muestra que, al menos entre 1971 y 1981, solamente el 20 por ciento de ellos no tuvo participación destacada de algún grupo constituido o de alguna organización. Según Fonseca los sindicatos y juntas de acción comunal venían orientando paros cívicos desde el comienzo de la década del setenta, pero su presencia en los comités directivos de los paros sólo es significativa a partir de $1977^{23}$.

En cuarto lugar, la Acción Comunal ha buscado convertirse en una organización autónoma sin perder su carácter institucional, al tiempo que ha venido adoptando patrones de organización muy similares a los del sindicalismo. Entre los aspectos más notables de esta compleja transformación cabe mencionar los siguientes:

1. Según el censo comunal, el 78 por ciento de las juntas habrían sido creadas por iniciativa de la comunidad, el 11,6 por ciento por iniciativa de promotores y el 10 por ciento restante por autoridades, directorios políticos, iglesia y educadores. Aunque estos datos pueden estar un poco sesgados en tanto que provienen de las respuestas dadas por directivos de las juntas censadas, son un indicio del peso que la iniciativa comunitaria ha venido adquiriendo en la expansión de esta organización.

2. Las fuentes de financiación de las actividades y las obras realizadas por las juntas comunales indican que en 1993 los aportes municipales, las actividades de financiación propias (bazares, bingos, etc) y las cuotas de los afiliados tenían un peso considerable en la mayor parte de ellas. Con respecto a los auxilios departamentales y nacionales, el censo indica

22. Para una nueva visión del papel de la Acción Comunal en las zonas rurales véase: Universidad del Valle-Universidad de los Andes, Proyecto de desarrollo de metodología de evaluación de impacto y levantamiento de linea de base del programa de desarrollo integral campesino, PDIC, informe final, Agosto 1992, Bogotá pgs. 317-329.

23. Fonseca, Luz Amparo, Los paros civicos en Colombia, Revista “Desarrollo y Sociedad”, Estudios Laborales, Universidad de los Andes, cuaderno $\mathrm{N}^{\circ} 3$, Bogotá Mayo 1982, pgs. 24-25. 
que estos constituían una de las principales fuentes de financiación del 30 por ciento de las juntas.

Con la eliminación de los auxilios parlamentarios la autonomía política de las juntas comunales podría reforzarse, siempre y cuando éstas mejoren su capacidad técnica para la elaboración de proyectos autogestionarios y para la suscripción de contratos con las entidades públicas de orden municipal, departamental y nacional.

3. La formación de asociaciones municipales y regionales y de una confederación nacional ha sido otro factor decisivo en la autonomización de la Acción Comunal. Entre 1970 y 1973 se realizaron trece congresos nacionales, de los cuales los de 1983 y 1985 tuvieron particular importancia por cuanto que estimularon la creación de nuevas instancias de coordinación nacional, a saber: la Comisión Nacional de Seguimiento, la Secretaría Operativa y la Comisión Nacional Coordinadora Comunal; además, en esos eventos se adoptaron como tareas centrales la capacitación, la organización y la autonomía. A partir de estas orientaciones se fue desarrollando una nueva estructura que en el momento actual está constituida por 42.582 juntas de base, 644 asociaciones municipales, 28 federaciones regionales y la Confederación Comunal Nacional. Esta última fue creada durante el Congreso de Pereira, celebrado en 1990.

Con excepción de los departamentos de Guaviare, Vaupes y Vichada, en las demás regiones del país existen organizaciones comunales de segundo y tercer grado. Es posible que estas nuevas instancias estimulen la aglutinación de las juntas de base alrededor de reivindicaciones de mayor alcance, así como su participación en los proyectos y organismos públicos contemplados en el Estatuto General de Contratación Pública y la Ley de Participación Ciudadana.

Si bien es posible que este tipo de estructura, escalonada territorialmente, aumente la capacidad de presión de la Acción Comunal, no es descartable que genere mayores pugnas políticas y personales por el control de los aparatos directivos y que estimule una sobrevaloración de las reivindicaciones y acciones generales en detrimento de la atención a las necesidades y formas de trabajo propias de las comunidades de base. En el caso de que no se neutralicen las pugnas por el control de los nuevos aparatos directivos y no se establezca una relación adecuada entre las reivindicaciones locales, regionales y nacionales, es previsible que la Acción Comunal sufra una crisis similar a la que hoy padecen las organizaciones sindicales.

Por lo demás, no hay que olvidar que en el nuevo contexto legislativo la Acción Comunal podrá fortalecerse en la medida en que supere serias limitaciones, entre las cuales cabe destacar la ínfima participación de sus miembros y directivos en las diferentes instancias legislativas, su escasa experiencia en la formulación y gestión de proyectos de orden municipal, regional y nacional y la carencia de formación técnica y política de buena parte de sus directivos.

\section{LOS SINDICATOS}

La organización sindical atraviesa por una crisis sin precedentes en su historia. En las dos últimas décadas la proporción de trabajadores sindicalizados descendió del 16 por ciento al 6,7 por ciento, siendo la tasa de sindicalización en Colombia una de las más bajas en América Latina. Desde 1977, cuando se realizó el primer Paro Cívico Nacional con un notable liderazgo sindical, no han ocurrido movilizaciones de envergadura semejante. Las confederaciones sindicales tampoco han obtenido logros significativos en reivindicaciones de orden nacional. La reagrupación producida a mediados de los ochenta en torno a las nuevas centrales, CUT y CTDC, y la fusión de esta última con la CGT en 1992, no parecen haber aumentado substancialmente la capacidad de negociación y movilización del sindicalismo colombiano. Y, como si esto fuera poco, cerca de 1.500 líderes y activistas sindicales han sido asesinados en el curso de la última década.

La distribución de la población sindicalizada en las cuatro confederaciones existentes, según el censo de 1990, era la siguiente: CUT: 57,27 por ciento, CTDC: 10,77 por ciento, CTC: 7,85 por ciento, CGT: 3,95 por ciento. Con la fusión de la CTDC y la CGT en la CGTD varió esta distribución pero no se conocen las nuevas cifras. El reagrupamiento de los sindicatos en estas tres confederaciones ciertamente ha significado un progreso con respecto a la extrema fragmentación de la década del 80. Sin embargo, las nuevas centrales CUT y CGTD, aún están lejos de lograr la "unidad en la diversidad ideológica” y todavía el 20 por ciento de los sindicalizados se mantiene por fuera de sus toldas ${ }^{24}$.

En estudios anteriores analizamos las posibles causas de la debilidad estructural del sindicalismo colombiano, como también la incidencia de los períodos de recesión económica y las políticas de reestructuración industrial en el descenso de la tasa de sindicalización ${ }^{25}$. En la medida en que estos análisis no parecen haber sido desvirtuados por los sucesos de los últimos años ni por nuevos estudios, nos limitaremos a actualizarlos presentando un resumen de los principales cambios económicos y laborales de los últimos cuatro años y sus posibles efectos en la organización sindical.

Desde el punto de vista económico los problemas más fuertes que enfrentó el sindicalismo en la década pasada estuvieron relacionados con los efectos laborales de la recesión económica (1980-83), la reestructuración industrial y las restricciones salariales impuestas en el marco de las políticas antiinflacionarias. A los procesos de reestructuración industrial y la política de restricción salarial, se han sumado en los últimos dos años, el impacto de la apertura económica y la "Modernización del Estado" en el ámbito laboral. La consideraciones siguientes dan una idea de los nuevos problemas que enfrenta el sindicalismo.

24. Ibid, pgs. $44,45,49$

25. Cfr. Gómez, Hernando, Londoño, Rocío y Perry Guillermo. Sindicalismo y Política Económica, editorial Fedesarrollo-Fescol-Cerec, Bogotá 1986, cap. III. Londoño, Rocío, Problemas laborales y reestructu ración del sindicalismo, en "Al filo del Caos", editorial Tercer MundoInstituto de Estudios Políticos y Relaciones Internacionales, U. Nal., Bogotá 1989, segunda parte, cap. 5. 
La flexibilización del empleo, como una de las políticas importantes de la reestructuración industrial y la apertura, ha provocado una sustitución progresiva de empleos permanentes por empleos temporales que ha afectado la estabilidad laboral. Según Alvaro Zerda, en la década del ochenta el personal temporal empleado en la industria aumentó a una tasa del 25 por ciento promedio anual. Por su parte Hugo López estima que entre 1984 y 1992 la proporción de trabajadores temporales empleados en las empresas privadas de las cuatro áreas metropolitanas ascendió del 15,2 por ciento al 20,3 por ciento; con todo, López considera que el problema más notable consiste en que "casi la tercera parte de los nuevos enganches se están haciendo bajo la modalidad de trabajo temporal" ${ }^{26}$.

La introducción de nuevas tecnologías ha comenzado a modificar las cualidades exigidas al trabajador y las formas de trabajo en las empresas. A este respecto Zerda menciona cuatro cambios importantes: enganche de bachilleres incluso para los niveles más bajos, trabajadores polivalentes o versátiles en el puesto de trabajo, altas calificaciones en el caso de actividades de mantenimiento de equipos electrónicos, y mayor peso de formas cooperativas de trabajo.

No obstante, como lo advierte Mauricio Cárdenas esta no ha sido la única tendencia en la reestructuración del sector productivo: "paralelamente a la actualización tecnológica de las empresas líderes se ha dado un proceso de informalización y desconcentración de las actividades manufactureras con efectos contrastantes en la fuerza laboral" ${ }^{27}$. La dispersión de los trabajadores y la heterogeneidad de las condiciones laborales, acentuada por la informalización del empleo, ha dificultado aún más la ampliación de la organización sindical y el diseño de una política reivindicativa de carácter global. Por lo demás, esta situación se ha visto agravada por la carencia de modalidades de organización sindical adecuadas para los trabajadores "informales" y por la rutinización de las tácticas de afiliación.

En el sector público los problemas más notables han estado asociados al programa de "Modernización del Estado" de la administración de los presidentes Gaviria y Samper. La privatización de empresas públicas y la reestructuración de las entidades estatales han conllevado la indemnización de un número considerable de trabajadores, la reubicación de unos cuantos y la reducción de las nóminas de personal. La Central Unitaria de Trabajadores, CUT, estima que 77.830 trabajadores salieron de la nómina oficial por este programa en el año de 1992. Sin embargo, en la evaluación del programa de modernización hecha por la Contraloría General de la República en 1993, se afirma que la reducción en la nómina de las entidades reformadas hasta ese momento fue del 6 por ciento, la cual significó la desvinculación de 23.379 empleados ${ }^{28}$. Con respecto a los efectos del programa de modernización estatal en la organización, Norberto Ríos estima que éste ha sido la causa de la pérdida de 40.000 afiliados de los sindicatos del sector público ${ }^{29}$.

Por otra parte, la Ley 50 de 1990 introdujo modificaciones sustanciales en la legislación laboral, la mayor parte de las cuales fueron rechazadas por los organismos sindicales. Entre los cambios que vulneraron las antiguas conquistas laborales los sindicalistas han subrayado los siguientes: la flexibilización de la contratación, la reducción de la estabilidad laboral y la eliminación de la retroactividad de las cesantías en los contratos suscritos a partir de la vigencia de la ley ${ }^{30}$. No obstante, sobre las virtudes y limitaciones de esta reforma laboral existen otras consideraciones que conviene registrar. A diferencia de los sindicalistas, que rechazaron globalmente la Ley 50, Hugo López muestra que los efectos de la reforma del régimen de cesantías y de despidos son complejos y diferenciados:

Primero, al disminuir la onerosa carga prestacional ocasionada por la retroactividad de las cesantías, el nuevo sistema ha contribuido a reducir la inestabilidad laboral de los nuevos trabajadores.

Segundo, la abolición de las cláusulas del antiguo código laboral, que hacían "prohibitivos" los despidos después del décimo año de antigüedad, conllevó la supresión de los incentivos para que las empresas despidieran a los trabajadores antes de cumplir los 10 años de servicio. Esta modificación ciertamente acentuó la inestabilidad de los trabajadores más antiguos pero hasta el momento su efecto ha sido moderado.

Con respecto a los efectos de la Ley 50 en la estabilidad laboral López concluye lo siguiente: "Con todo no conviene cantar apresuradamente victoria. Primero porque la inestabilidad laboral de los asalariados sigue siendo muy elevada: una probabilidad de despido en el primer año del 41 por ciento en las microempresas y del 27 por ciento en las medianas y las grandes sigue siendo aterradora. Segundo porque a pesar de que la demografía ayuda (la mano de obra juvenil, educada y barata, empieza a escasear y escaseará más en el futuro), faltan estímulos para lograr que los escalafones premien la productividad y por tanto promuevan una mayor estabilidad".

Tercero, la reforma parecer haber contribuido a reducir la evasión del pago del salario mínimo mensual en las empresas medianas y grandes, mediante la nueva obligación de pagar el dominical en proporción al tiempo semanal de trabajo. La tendencia parece haber sido de contratar trabajadores de menos de 48 horas semanales. En el caso de las microempresas la nueva norma no ha tenido efecto

26. Zerda Alvaro, Modernización empresarial y empleo en la industria manufacturera colombiana, en "Cambio técnico, empleo y trabajo en Colombia”, FESCOL, Bogotá 1993, pg. 45. López Hugo, Contexto macroeconómico colombiano, mercado laboral urbano y retos para una política de empleo, Op. Cit., pg. 27.

27. Cárdenas Mauricio, Apertura económica y reconversión industrial: impacto laboral y respuesta sindical, "Cambio técnico, empleo y trabajo", Op. Cit., pg. 160.

28. Cfr. CUT, Derechos humanos y movimiento sindical, Informe de la Central Unitaria de Trabajadores de Colombia a la OIT, Santafé de Bogotá, 1994, pg. 12. FEDESARROLLO-IEPRI, Situación colombiana, enero, 1994, N. ${ }^{\circ} 7$, pg. 42.

29. Ríos, Norberto, Efectos neoliberales en el sindicalismo, artículo publicado en "Caja de herramientas", Corporación SOS colombiana, Bogotá, agosto 1993, año 3 N.o 20 pg. 15.

30. Cfr. Nieto, Enmanuel, El nuevo regimen de la liquidacion y administración de cesantía, un balance preliminar, Revista de la ENS, Escuela Nacional Sindical, Medellín, diciembre 1993, N. ${ }^{\circ} 30-31$, pgs. 26-33. 
alguno por cuanto que la evasión del pago del salario mínimo aumentó.

Cuarto, "la reforma parece haber promovido un incremento en la jornada laboral de los asalariados, al reducir los costos de horas extras, nocturnos y dominicales...". Por otra parte, la flexibilidad de las jornadas ha producido un incremento de los empleos de tiempo parcial y por horas, los cuales son demandados por muchos trabajadores y en particular por las mujeres ${ }^{31}$.

Finalmente, ha de tenerse en cuenta que la Ley 50 también introdujo cambios como la simplificación de los trámites para la constitución de sindicatos, el fortalecimiento de la negociación colectiva y la participación de representantes de los trabajadores en diferentes instancias que tiene que ver con las políticas y el manejo de los asuntos laborales.

Sin duda alguna, todos estos cambios han significado un viraje drástico en la orientación de la economía nacional y en la gestión de la fuerza laboral. Sus efectos en la dinámica sindical han sido más traumáticos de lo que cabría esperar debido a que los dirigentes se han colocado en una posición de defensa a ultranza de reivindicaciones laborales tradicionales y han mostrado escasa capacidad en la formulación de políticas y tácticas que les permita a los sindicatos afrontar adecuadamente la nueva situación y ofrecer alternativas a los trabajadores nuevos. Aunque desde comienzos de la década del ochenta, la recesión y la crisis industrial dieron un campanazo al rutinarismo sindical, todo parece indicar que los dirigentes no asimilaron a fondo la lección; tal vez pensaron que acelerando procesos de fusión, acudiendo casi exclusivamente a retóricas y tácticas de resistencia y repitiendo la convocatoria a jornadas nacionales de protesta, podrían detener las reestructuraciones y medidas en curso, o al menos minimizar los efectos sobre sus afiliados y su propio poder.

Uno de los síntomas más visibles de la difícil situación del sindicalismo es la reducción de su influencia en el conjunto de la población trabajadora del país. En los últimos ocho años el número de los trabajadores sindicalizados apenas se incrementó en 13000 miembros mientras que la población ocupada nacional tuvo un incremento muy superior. Este desfase se advierte en el descenso de la tasa de sindicalización del 9,3 por ciento al 6,7 por ciento entre 1984 y $1992^{32}$. La pérdida de afiliados afectó principalmente a los sectores de Transporte y Comunicaciones, Electricidad, Gas y Agua, Minas y Canteras. Con excepción de los establecimientos financieros, en los cuales la afiliación sindical aumentó un dos por ciento, en los demás sectores la afiliación sindical disminuyó con respecto al número de trabajadores ocupados en cada uno de ellos.

La distribución de la afiliación sindical por ramas de actividad muestra que el sindicalismo colombiano está compuesto en una alta proporción por trabajadores de los servicios ( 44,1 por ciento), con predominio de las organizaciones estatales, $y$, en menor medida, por trabajadores de la industria ( 15,5 por ciento), el transporte y las comunicaciones ( 15,1 por ciento); los demás sectores apenas aportan un poco más del 25 por ciento de los afiliados. En las últimas tres décadas la composición del sindicalismo ha variado sensiblemente a favor de los trabajadores de los servicios, los establecimientos financieros y el comercio, en tanto que el peso de los trabajadores de la industria, el transporte, la construcción y el sector agropecuario ha ido descendiendo. De continuar esta tendencia en pocos años tendremos un sindicalismo dominado por los empleados de "cuello blanco" y una población obrera muy desprotegida.

Ahora bien, si se examina la sindicalización en cada una de las ramas de la actividad económica se observan niveles de organización bastante desiguales. Los sectores con mayores niveles de organización son: Electricidad, Gas y Agua ( 42,0 por ciento), Transporte y Comunicaciones (27,4 por ciento), Servicios ( 18,4 por ciento) y Establecimientos Financieros (14,3 por ciento); no sobra señalar que en estos sectores el peso de los sindicatos estatales es notable. Aunque en orden de magnitud los sindicalizados del sector industrial constituyen el segundo grupo de la estructura sindical, su proporción con respecto al número total de trabajadores de la industria manufacturera es apenas del 8,2 por ciento.

El impacto que las medidas y cambios económicos recientes han tenido sobre la organización sindical se percibe en las variaciones de las tasas sectoriales de sindicalización durante los últimos ocho años:

1. El único grupo que aumentó su nivel de sindicalización fue el de los trabajadores del sector financiero: la tasa de sindicalización pasó del 12,7 por ciento en 1984 al 14,3 por ciento en 1990.

2. La proporción de trabajadores sindicalizados en la industria manufacturera se mantuvo en poco más del 8 por ciento.

3. Los demás sectores presentaron descensos en sus tasas de sindicalización. Las pérdidas más fuertes se presentaron en el sector de Transporte y Comunicaciones con una disminución neta de $83.500 \mathrm{sin}$ dicalizados y un descenso del 24 por ciento en la tasa de sindicalización; en el sector agropecuario disminuyó en 6.800 el número de sindicalizados y la tasa descendió un 0,3 por ciento; en la construcción, se perdieron 1.000 afiliados y la tasa bajó un 0,8 por ciento. Los sectores en los cuales aumentó levemente el número de afiliados pero disminuyó la tasa de sindicalización fueron: Electricidad, Gas y Agua (-9 por ciento), Minas y Canteras (-8 por ciento), Servicios $(-1$ por ciento) y Comercio, Restaurante y Hoteles $(-0,3 \text { por ciento })^{33}$.

31. López, Hugo, Op. Cit., pgs. 30-32

32. Cfr. Ríos, Norberto, El sindicalismo colombiano hoy, Revista de la ENS, Escuela Nacional Sindical, Medellín, N. ${ }^{\circ} 25-26$, agosto 1992, pgs. 62-67; Efectos neoliberales en el sindicalismo, artículo publicado en "Caja de herramientas", Corporación Viva la Ciudadanía, Bogotá, año 3, N. . 20, agosto 1994. El equipo de la Escuela Nacional Sindical, en el cual trabaja Norberto Ríos, ha hecho nuevas estimaciones sobre la tasa de crecimien to del empleo en los períodos 1973-1985 y 1985-1992 que dan como resultado una reconsideración del número de trabajadores ocupados en 1992, el cual ascendería a 13.267.707. Si nos atenemos a esta nueva cifra que parece más cercana a la realidad la tasa de sindicalización de 1992 sería del 6,7 por ciento y no del 6,18 por ciento, aunque la variación no es muy significativa vale la pena consignar esta precisión hecha por Ríos y la ENS.

33. III Censo Nacional Sindical, Op. Cit., pg. 47. 
El decrecimiento de la población de trabajadores sindicalizados ha estado muy influido por dos tipos de problemas: por una parte, los procesos de reestructuración industrial y modernización del Estado han conllevado desplazamientos de trabajadores permanentes por trabajadores temporales en la industria y, despidos, indemnizaciones y reducciones en las nóminas del sector estatal. Por otra parte, el tipo de respuestas sindicales a estos procesos han puesto mayor énfasis en la resistencia y la opción pasiva que en los esfuerzos de renovación y flexibilización de las políticas de negociación y de las formas de reclutamiento y acción sindical. Para los dirigentes sindicales y algunos estudiosos la pérdida de peso del sindicalismo se ha debido más a "la política antisindical de los patronos", expresada principalmente en el incremento del número de pactos colectivos, que a la disminución de empleos por efecto de la apertura y a la incapacidad de los sindicatos para afrontarla. Sin embargo, algunos admiten que la política patronal ha "causado mayores estragos en aquellas empresas donde el sindicato ha asumido actitudes intransigentes y contestatarias" ${ }^{34}$.

\section{LAS HUELGAS}

Lo primero que llama la atención en la trayectoria sindical colombiana es la escasa utilización de la huelga. Con base en una serie histórica de huelgas y huelguistas en los últimos 30 años, Alvaro Delgado afirma que "la mayoría de las empresas en Colombia nunca han experimentado una huelga" ${ }^{35}$. En un estudio publicado en 1986 anticipamos algunas explicaciones de este fenómeno que aún parecen válidas. En el caso colombiano, el uso de la huelga ha sido particularmente restringido no sólo por los riesgos inherentes a este tipo de acción, sino por la restricción de su legalidad al proceso de negociación de pliegos y la baja cobertura de la organización sindical. A estas limitaciones se suma el predominio de una mentalidad empresarial que no termina de aceptar los mecanismos modernos de presión y de solución de los conflictos laborales y que ha buscado impedir la existencia de los sindicatos por diversos medios.

En estas condiciones hacer una huelga exige por lo menos una organización sólida que pueda resistir los embates patronales y sortear las restricciones legales. No sorprende entonces que el uso de la huelga o del paro, prácticamente haya estado circunscrito a los trabajadores de las grandes empresas privadas y a los obreros y funcionarios del sector público que son quienes cuentan con sindicatos sólidos y mayor poder de presión. Por razones de orden legal las huelgas han estado estrechamente vinculadas al proceso de negociación de pliegos y a la exigencia del cumplimiento de las normas laborales; las huelgas por razones tales como la solidaridad de clase y la protesta social y política solo ocurren de manera esporádica y en aquellos sectores más influidos por las corrientes de izquierda. Dos indicadores evidencian estas tendencias:

1. En el lapso de 30 años (1961-1990), según la estadística elaborada por Delgado, ocurrieron 2.800 huelgas en las cuales participó un total de 10.610.701 trabajadores. En otros términos estas cifras indican la ocurrencia de un promedio de 96 huelgas por año con la participación de 365.862 trabajadores. Si se desglosan estos datos por sectores se advierte la gran incidencia de los maestros en el número de huelguistas: de los 10.610.701 huelguistas casi el 60 por ciento fueron maestros.

2. El 90 por ciento de las huelgas de este período ocurrió por pliegos de peticiones no resueltos y por violación de normas laborales y cláusulas convencionales. Las huelgas de solidaridad gremial y protesta han sido apenas el 10 por ciento del total.

Desde un punto de vista jurídico sobresale la arbitrariedad en el manejo de las relaciones y los conflictos laborales en Colombia: que el 47,9 por ciento de las huelgas de tres décadas haya ocurrido por violación de normas laborales y cláusulas convencionales revela la tenaz resistencia del sector patronal a acatar la legislación laboral básica, como también la fragilidad del régimen de sanciones y la laxitud del Estado frente a este tipo de transgresiones. Por otra parte, de la infracción de normas laborales básicas tampoco ha estado exento el Estado. El incumplimiento reiterado en el pago oportuno del salario y las prestaciones sociales a los maestros, el frecuente desconocimiento de la carrera administrativa de los funcionarios públicos y de acuerdos pactados en convenciones colectivas, que por conveniencias políticas han ignorado, la situación financiera de las empresas estatales se encuentran entre los principales motivos de los paros realizados por los empleados públicos.

El "Estado social de Derecho" consagrado en la Constitución del 91 no parece amparar aún a buena parte de los trabajadores. Al contrario de lo que cabría esperar durante el último cuatrenio la proporción de huelgas causadas por violación de normas laborales y cláusulas convencionales alcanzó la absurda cifra del 51,5 por ciento del total. Las huelgas de protesta política también aumentaron de manera significativa: 71 huelgas, que representan el 16,5 por ciento del total del cuatrenio, fueron motivadas principalmente por asesinatos, atentados, detenciones y persecución a dirigentes y activistas sindicales. De las huelgas políticas sólo el 7 por ciento fueron actos de oposición a la política económica de la administración Gaviria.

Con todo, las jornadas de protesta los paros convocados por las centrales sindicales para denunciar y detener la "guerra sucia" contra los dirigentes y activistas sindicales y para expresar su rechazo a las medidas económicas oficiales han contado con un precario respaldo. Del conjunto de movilizaciones y jornadas realizadas quizás el mayor éxito lo obtuvieron los sindicatos que lograron detener la privatización del SENA y TELECOM, impidieron el cierre de Alkalis y la Concesión Salinas y consiguieron escapar al nuevo sistema de Seguridad Social ${ }^{36}$.

34. Ríos, Norberto, Op. Cit.

35. Delgado, Alvaro, El conflicto laboral colombiano, CINEP, Bogotá, 1994, inédito. Gaviria frente al sector popular: del dicho al hecho..., "Cien Días", CINEP, mayo-julio, vol. 6, N." 28.

36. Delgado, Gaviria frente al sector popular.., Op. Cit., pg. 21. 


\section{EL PACTO SOCIAL}

Entre los cambios más recientes en la política sindical sobresale la participación de las centrales obras en el Pacto de Productividad, Precios y Salarios propuesto por el presidente Samper. Como su nombre lo indica, este pacto busca disminuir la tasa de inflación, recuperar la capacidad adquisitiva de los salarios y aumentar los índices de productividad en el conjunto de las actividades económicas, mediante la concertación entre el gobierno, los empleadores y los sindicatos. Si bien es cierto que la concertación de políticas macroeconómicas hasta ahora comienza a ensayarse en Colombia, no hay que olvidar las experiencias del Consejo Nacional de Salarios (1984-1986) y del Consejo Nacional Laboral (1987-1994) en lo que respecta a la negociación del salario mínimo anual y a los intentos fallidos de concertar otros asuntos de carácter laboral ${ }^{37}$.

En el marco del Pacto Social se han producido hasta ahora dos negociaciones. La primera se llevó a cabo en diciembre de 1994 y consistió en la fijación del aumento del salario mínimo para 1995 con base en la tasa de inflación esperada para ese año (18 por ciento) y el índice de productividad acordado (2,5 por ciento). El incremento del 20,5 por ciento en el salario mínimo se convirtió de hecho en el punto de referencia para los aumentos salariales en el sector público y para las negociaciones colectivas. En la segunda negociación, realizada en diciembre de 1995, se estableció el aumento del salario mínimo para 1996 en un 19,5 por ciento con base en la meta de inflación del 17\%, fijada por el Banco de la República, y un índice de productividad de 2,5 por ciento.

Con respecto a las negociaciones que solían hacerse en Consejo Nacional Laboral, se advierte dos aspectos nuevos: por una parte, la incorporación de un índice de productividad en la fijación del salario, aunque pocos saben cómo se calcula. Por otra parte, el compromiso del gobierno con una meta de inflación que lo obliga a un política más seria de control de precios y de manejo del gasto público. Con todo, al menos desde el punto de vista de los sindicalistas y los empleadores, los resultados del Pacto en 1995 no fueron los esperados.

Los dirigentes sindicales comprometidos con la concertación admiten que el índice de inflación disminuyó en un 2,02 por ciento con respecto al registrado en 1994, pero critican los efectos negativos que, a su juicio, tuvo la política de contracción monetaria impuesta por el Banco de la República. A esta política le atribuyen efectos indirectos tales como "los cierres y concordatos empresas, la disminución del empleo industrial, la no generación de los empleos previstos en el sector público y la disminución de la demanda". Tampoco se muestran satisfechos con los efectos del Pacto sobre el comportamiento de los precios por cuanto que "74 artículos de la canasta familiar, que representan el 37,95 por ciento del total, han superado el 18 por ciento...". Si bien reconocen que los actores de esta concertación se han acercado "a una comprensión más detallada del concepto y la medición de la productividad", advierten que los trabajadores todavía asocian la productividad con la sobreexplotación de la fuerza de trabajo debido a que éste era el énfasis que le habían dado los empresarios y el gobierno. En términos de los resultados específicos en este campo, los sindicalistas afirman lo siguiente: "La información del Ministerio de Trabajo nos señala que el 64 por ciento de las convenciones colectivas firmadas no registraron aumentos salariales por encima del 21 por ciento. Ello quiere decir que no se ha tenido en cuenta el Pacto de convenir reajustes salariales convencionales que contemplen la productividad y los márgenes de ganancia de los empleadores" ${ }^{38}$.

Pero además de la negociación del monto del salario mínimo, por presión de los representantes sindicales, la concertación de 1924 incluyó un acuerdo sobre "fortalecimiento del movimiento sindical". Para el desarrollo del mismo se creó una comisión tripartita, adscrita al Ministerio de Trabajo, cuya misión consiste en "analizar los artículos de la Constitución relacionados con los derechos y garantías sindicales y su correspondiente aplicación...". Respecto a este compromiso los dirigentes sindicales destacan tres resultados positivos: la elaboración de dos proyectos de ley, una para la reestructuración del Ministerio de Trabajo y otro para garantizar el fuero sindical a los dirigentes del sector público, la formación de varias comisiones para estudiar algunos problemas laborales y sindicales y diseñar programas de capacitación en diferentes áreas, y la concesión de un espacio semanal en la Televisión Nacional para la discusión y divulgación de temas laborales y sindicales ${ }^{39}$.

Aunque el trecho recorrido hasta ahora es demasiado corto para hacer una evaluación seria del Pacto Social, hay indicios fuertes de que su porvenir de modo alguno está asegurado. A las críticas hechas por los dirigentes sindicales más comprometidos con esta política, se suman el descontento de los gremios patronales con el incumplimiento de los compromisos del gobierno en materias tales como la austeridad en el gasto público y los incrementos en las tarifas de los servicios públicos y también las observaciones de instituciones académicas como FEDESARROLLO en el sentido de que la disminución de la inflación no puede ser atribuida al Pacto Social. Por otra parte, el apoyo sindical en lugar de aumentar ha disminuido notoriamente. De la mesa de negociaciones se retiró la CGTDC, segunda central en importancia numérica, y más de la tercera parte de los delegados al Tercer Congreso de la CUT votaron en contra de que ésta organización continuara dentro del Pacto.

Tal vez el nombramiento del presidente de la CUT, Orlando Obregón, como Ministro de Trabajo, haya sido una medida desesperada del presidente Samper para ganar apoyo entre los trabajadores y salvar el Pacto Social. Sin embargo, la vieja táctica de la captación de líderes sindicales le ha reportado pocos beneficios a los gobiernos y a los trabajadores. En este caso lo que ha hecho el presidente Samper es sacar de la CUT a uno de los dirigentes más

37. Cfr. Perry y otros, Sindicalismo y política económica, Op. Cit. y Londoño, Problemas laborales y sindicalismo, Op. Cit.

38. Periódico Compromiso, Órgano informativo y de opinión del Frente Unitario de Trabajadores Demócratas, FUTD, integrante de la CUT, Santa Fé de Bogota, noviembre de 1995, separata. 39. Ibid. 
comprometidos con el Pacto Social y ponerlo a manejar un difícil escenario laboral.

El nombramiento de Obregón recibió el respaldo público del Frente Unitario de Trabajadores Demócratas, sector que tiene un peso relativamente importante en la CUT, pero las voces escépticas no se han hecho esperar y ya se han anunciado jornadas de protesta por el aumento del 19,5 por ciento en el salario mínimo. Con respecto a este nombramiento, el presidente de la CTC y el Secretario General de la CGTD afirmaron recientemente que Obregón "tiene la responsabilidad de borrar el mal sabor que les dejó a las centrales la administración del también sindicalista Jorge Carrillo durante el gobierno de Belisario Betancur... quien fue recordado como un funcionario que pasó sin pena ni gloria", también expresaron sus dudas de que el nuevo Ministro cuente con el respaldo político requerido para impulsar cambio prioritarios para el sindicalismo, entre los cuales destacan la modificación de normas relacionadas con la contratación individual y colectiva, la reestructuración del Instituto de Seguros Sociales y la generación de empleos productivos ${ }^{40}$.

\section{EL FUTURO PRÓXIMO}

Hacer ejercicios prospectivos en el caso colombiano nunca ha sido fácil y menos aún cuando la inestabilidad social y la incertidumbre política parecen ser los rasgos dominantes del panorama nacional. Aunque la Cámara de Representantes absolvió al presidente Samper de las acusaciones de que fue objeto en el trajinado "Proceso 8.000", en el momento no sabemos si logrará mantenerse en ejercicio de sus funciones hasta el 7 de agosto de 1998. De todos modos es evidente que la gobernabilidad del país está seriamente erosionada. Con todo, intentaremos formular unas pocas hipótesis sobre el porvenir de las organizaciones populares y sugerir algunos cambios que podrían detener su pérdida de peso en la dinámica social.

1. Partimos de la consideración de que en el corto plazo no parece viable un cambio substancial de las políticas económicas en curso, como tampoco un proyecto reformista con un fuerte acento social. Sin embargo, de ello no se desprende que las organizaciones populares no puedan actuar para obtener logros en campos tales como la distribución del ingreso, la calidad de vida de los asalariados y los sectores más pobres, la modernización de las relaciones laborales en el sector informal, la recuperación del poder adquisitivo de los salarios de los derechos de organización y expresión social y política. En nuestro concepto, uno de los principales desafíos que tienen ante sí las organizaciones sociales colombianas consiste en hacer pleno uso de los nuevos derechos sociales y políticos establecidos en la Constitución del 91 y en las leyes y decretos reglamentarios, de suerte que rompan los estrechos marcos de acción en los que han operado y aumenten de manera substancial su representatividad y su capacidad de presión y de negociación. Si bien es cierto que la pervivencia de viejas costumbres políticas y el uso recurrente de la violencia interfieren el desarrollo de los nuevos derechos, no lo es menos que el espacio de acción social y política hoy día es mucho más amplio que hace una década. Por lo demás, las condiciones para que las organizaciones sociales dejen de ser clientelas políticas y redefinan sus relaciones con los partidos parecen estar dadas.

2. Es previsible que los sindicatos sigan siendo la principal forma de asociación de los asalariados para asuntos tales como la negociación colectiva de la remuneración y de las condiciones de trabajo. Pero si persisten en sus posiciones constestarias y en la defensa a ultranza de modelos económicos utópicos y reivindicaciones poco viables, a la luz de políticas tales como la flexibilización del empleo, la racionalización de las nóminas del personal estatal y el creciente peso de la productividad y la capacitación en los factores que determinan el desempeño laboral y la remuneración, es muy posible que su cobertura y representatividad disminuyan aún más y que queden circunscritos a los trabajadores antiguos tanto del sector privado como del Estado.

Admitiendo que en Colombia los obstáculos interpuestos por los empresarios y por el Estado han sido muchos y muy frecuentes, no es poca la responsabilidad que los dirigentes sindicales han tenido en la severa crisis de la organización sindical. La brecha entre la retórica sindical y las prácticas conciliadoras, la rutinización y burocratización de los dirigentes, la mínima renovación de los cuadros directivos y la competencia clientelista por el manejo del aparato sindical, son problemas que requieren soluciones serias y oportunas. A estos problemas se suman hoy la corrupción que, a juicio de algunos analistas, se ha extendido incluso al sindicalismo de izquierda, y la instrumentalización de sindicatos importantes por parte de los grupos guerrilleros.

Con todo, la decisión del Tercer Congreso de la CUT de modificar los estatutos a fin de introducir el sistema de votación directa y secreta para la elección de los organismos directivos, es un síntoma de que los problemas mencionados comienzan a ser reconocidos. Aunque la adopción de un nuevo régimen electoral no está exenta de problemas, podría generar una renovación más amplia de la cúpula sindical y disminuir la presión política sobre los afiliados. Otra de las propuestas que se halla en curso es la implantación de la revocatoria del mandato a los directivos sindicales, mecanismo que, en caso de ser adoptado, indudablemente estimularía una mayor incidencia de los afiliados en la conducción de sus organizaciones. Sin embargo, el porvenir de la CUT es cada día más incierto, debido a la profunda división que padece.

3. Que más del 50 por ciento de los trabajadores se encuentren dispersos en pequeñas unidades eco-

40. El Tiempo, "Preparan jornada de protesta nacional. Compromisos del Ministerio de Trabajo”, enero 10 de 1996. sección B, pg. 6. 
nómicas y trabajen en condiciones muy disímiles, constituye uno de los obstáculos más fuertes para ampliar la sindicalización y unificar las luchas de los asalariados alrededor de reivindicaciones comunes. Sin embargo, los esfuerzos hechos por las confederaciones para crear modalidades de organización y formular una política que se ajuste a las condiciones y a las aspiraciones de estos sectores laborales han sido muy pocos. Organizar a los trabajadores informales e integrarlos a las luchas laborales constituye otro de los importantes retos del sindicalismo. Para ello sería conveniente un estudio de las experiencias que en este sentido se han tenido en otros países y de la trayectoria de los sindicatos de "oficios varios" y las organizaciones de los vendedores ambulantes en Colombia.

4. En cuestiones tales como la vivienda, el acceso a diversos productos de consumo doméstico y el mejoramiento de la calidad de vida, los sindicatos han venido perdiendo peso en tanto que las organizaciones cooperativas han ganado una influencia considerable. Más aún, el notorio incremento de las cooperativas de producción, como alternativa de asociación de los desempleados, los trabajadores informales y de aquellos que se resisten a la condición de asalariados, revela una pérdida de peso de los sindicatos incluso en campos que les han sido propios. Aunque la especialización de las organizaciones sociales es una tendencia mundial y hoy día resulta impensable que los sindicatos se ocupen de todas las aspiraciones y reivindicaciones de los asalariados, en el caso colombiano parece aconsejable una mayor atención por parte de los sindicatos, a aquellas aspiraciones de los trabajadores que van más allá del campo estrictamente laboral.

5. Que más del 40 por ciento de la población vive en condiciones de pobreza, no disponga de empleo e ingresos estables y sobreviva valiéndose de lo que en el argot popular se llama el "rebusque", es otro de los obstáculos fuertes para la ampliación de las organizaciones formales en Colombia. La situación de marginalidad de estos colombianos los obliga a una incesante búsqueda de medios de subsistencia para la cual se apoyan en la solidaridad familiar y vecinal, en agrupaciones comunitarias informales y en organizaciones de beneficencia y grupos religiosos. En la medida en que para estos grupos lo que está en juego es la subsistencia diaria, difícilmente pueden ser atraidos por las "ofertas" a mediano y largo plazo, como las que suelen hacer las organizaciones convencionales. Es muy posible que las juntas de Acción Comunal mantengan un peso considerable en la solución de problemas de los grupos rurales y urbanos más pobres, pero para ello tendrán que mejorar substancialmente su capacidad de formulación y gestión de proyectos sociales así como el alcance y la cobertura de los mismos.

6. Una revisión rápida de los motivos por los cuales se producen la mayoría de las huelgas y las protes- tas cívicas indica que los movimientos sociales siguen girando en torno a reivindicaciones tan básicas como el empleo, los salarios, la estabilidad laboral, la vivienda, la salud, la educación, las vías públicas y la tierra. Sin embargo, de la persistencia de estas reivindicaciones no se infiere que las viejas tácticas de organización y movilización continúen siendo las más eficaces, como tampoco que no sea preciso dar mayor importancia a las aspiraciones de los asalariados jóvenes y a las reivindicaciones promovidas por movimientos de género, ecológicos y culturales.

7. En casi todos los escritos sobre los movimientos sociales se subraya la dispersión y la falta de coordinación de los mismos al tiempo que se reitera la necesidad de la "UNIDAD". Los términos "dispersión", "atomización" y "Unidad" también hacen parte del léxico con el que los dirigentes de las organizaciones populares dan cuenta de sus debilidades y de la fórmula predilecta para superarla. En correspondencia con ese viejo diagnóstico, y a raíz del relativo éxito del Paro Cívico Nacional de 1977 convocado por el Comité Nacional de Solidaridad, los grupos de izquierda y los dirigentes de las organizaciones populares se entusiasmaron demasiado con la táctica de las coordinadoras nacionales. Con la esperanza de que, en el mediano plazo, las alianzas coyunturales darían lugar a "unidades orgánicas", durante los últimos 20 años se han creado un sinnúmero de coordinadoras ${ }^{41}$. De todos estos esfuerzos, tal vez los más efectivos han sido la creación de la ONIC, la CUT, la CGTD y la Coordinadora Nacional de juntas de Acción Comunal. Las demás coordinadoras han cumplido cierto papel en la elaboración de pliegos unificados de peticiones, en la organización de acciones de protesta y en la elaboración de algunas propuestas legislativas, pero no han aumentado substancialmente la capacidad de presión y de negociación a favor de sus afiliados y del conjunto de los sectores populares.

Si se tiene en cuenta la diversidad y heterogeneidad de las organizaciones existentes así como la inviabilidad de un proyecto socio-político que represente cabalmente ese haz de intereses, aspiraciones y formas de vida, no parece sensato seguir insistiéndo en la creación de "organizaciones únicas" de asalariados, vecinos, mujeres, comunidades étnicas, consumidores, etc. Con excepción de coyunturas extraordinarias en las que una buena parte de los sectores populares converge en alguna propuesta o en ciertas

41. Un seguimiento somero de estos esfuerzos indica que las dos últimas décadas se han creado por lo menos los siguientes aparatos de coordinación: Consejo Nacional de Solidaridad (1976), Coordinadora Nacional de Grupos Eclesiales de Base (1979), Comité Coordinador Nacional Sindical (1981), Comité Nacional Unitario (1981), Comité de Unidad del Sindicalismo Independiente (1982), Coordinadora Nacional Indígena (1982), Coordinadora Nacional de Organizaciones Agrarias (1984), Coordinadora Nacional de Asociaciones de Vivienda Popular (1985), Coordinadora Guerrillera Simón Bolivar (1985), Comité Nacional pro-centra Unitaria (1985), Consejo Nacional de Solidaridad Sindical (1987). 
demandas al Estado, las luchas sociales parecen discurrir de manera segmentada y con distintos ritmos. La vieja aspiración de la izquierda y de algunos analistas sociales de crear un "movimiento popular unitario" de carácter permanente no solamente ha sido desvirtuada por acontecimientos pasados y recientes, sino que cada vez parece menos factible debido a la creciente diversificación de los grupos sociales, los intereses, las relaciones y las formas de interacción en las sociedades contemporáneas. En las condiciones de hoy tal vez sería más útil y viable imaginar formas más eficaces de coordinación y colaboración alrededor de reivindicaciones concretas, establecer acuerdos intersectoriales y fomentar antiguos y nuevos nexos de solidaridad social.

La insistencia de algunos investigadores y dirigentes sociales en la necesidad de crear una "sociedad civil" altamente organizada, cohesionada y participativa parece ignorar en qué país vivimos como también las tendencias a la fragmentación social que padecen incluso las naciones con sociedades civiles tradicionalmente fuertes. En lugar de tener como referencia una "sociedad civil" utópica, quizás sería más pertinente pensar en cuales serían los grados y las modalidades de asociación y participación más viables y eficaces. Una aspiración factible sería que en la mayoría de los hogares populares uno de sus miembros participara en alguna asociación comunal o vecinal y otro en un sindicato, puesto que de esa manera los ejes básicos de la organización social se desarrollarían considerablemente y las demás formas de asociación y participación serían ganancia.

\section{BIBLIOGRAFÍA Y DOCUMENTOS CONSULTADOS}

ANUC, ;De pie! y con ganas de echar p'alante, ponencias y conclusiones del Congreso de Unidad y reconstrucción de ANUC, Bogotá, agosto 26-27,1987.

ANDRI, El surgimiento de la ANDRI en las luchas campesinas, Bogotá, sin fecha, archivo ANDRI.

Archila, Mauricio, Cultura e identidad obrera, Colombia 1910-1945, CINEP, Bogotá, 1991

AROCHA, JAIME, Cultura afrocolombina, entorno y derechos territoriales, en "La política social en los años 90", Universidad Nacional de Colombia, Bogotá, 1994. Los negros y la Nueva Constitución de 1991, Revista "América Negra”, Universidad Javeriana, Bogotá, junio 1992, N. ${ }^{\circ} 3$.

Bell, Daniel \& Held, Virginia, The comunity revolution, en "The cities in change, studies on the urban condition”, Inc. Boston, 1973.

CANTILlo, José María, Vinculación de la organización comunitaria al desarrollo, Cuadernos ESAP, Bogotá, enero 1988, N. ${ }^{\circ} 15$.

CÁrdenas, Miguel Eduardo y Otro, Modernidad y Sociedad política en Colombia, Fescol-Fooro-Iepri, Bogotá, 1993.

Cardona, Guillermo, A los dirigentes comunales. Sobre autonomía comunal, Pasto, noviembre, 1985.

Carvajal, Carlos, Participación comunitaria: promoción y desarrollo, Alcaldía Mayor de Santafé de Bogotá, 1992.

Colegio Verde de Villa de Leyva, Cuadernos Verdes, Santafé de Bogotá, Nos. 1-8.
CONSEJERÍA PARA LA JUVENTUd, LA MUJER Y LA FAMILIA, Segundo y tercer informe periódico de Colombia presentado ante el comité para la eliminación de la discriminación contra la mujer, PNUD, Santafé de Bogotá, enero 1994. Política integral para las mujeres colombianas, marzo 8, 1993.

Cut, Derechos Humanos y Movimiento Sindical, informe a la OIT, Santafé de Bogotá, 1994.

Delgado, Alvaro, El conflicto laboral colombiano, 1961 1990, documento inédito, CINEP, 1994. Gaviria frente al sector popular: del dicho al hecho..., Revista "Cien Días”, CINEP, Bogotá, mayo-julio 1994, vol. 6, N. ${ }^{\circ} 26$.

DiGIDEC, Censo nacional calificado de juntas de acción comunal 1993, Ministerio de Gobierno, Bogotá, noviembre 1993. El desarrollo de la comunidad en Colombia, Bogotá, 1979.

Dombois, RaIner y PRIES, Ludger, Modernización empresarial: tendencias en América Latina y Europa, FESCOL-NUEVA SOCIEDAD, Caracas 1993.

ECofondo, Materiales de trabajo 1 y 2, Boletín Año 2, Bogotá, febrero-marzo 1994.

FEDESARROLlo-IEPRI, Situación colombiana, Bogotrá, enero $1994, \mathrm{~N}^{\circ} 7$.

Fonseca, Luz Amparo, Los paros cívicos en Colombia, Revista "Desarrollo y Sociedad", Cuaderno de Estudios Laborales, Universidad de los Andes, Bogotá, mayo $1982, \mathrm{~N}^{\circ}{ }^{\circ} 3$.

Foro Nacional pOR Colombia-InURBe, Evaluación de organizaciones de vivienda popular en Santafé de Bogotá, diciembre 1993.

FundACIÓN NATURA, Informe Amual 1992, Bogotá 1992.

GÓmez, B., Hernando y OTROs, Sindicalismo y política Económica, Fedesarrollo-Fescol-cerec, Bogotá 1986.

Gros, Christian, Derechos Indígenas y nueva Constitución en Colombia, Revista "Análisis Político", Instituto de Estudios Políticos y Relaciones Internacionales, Universidad Nacional de Colombia, Bogotá, mayoagosto $1993, \mathrm{~N} .{ }^{\circ} 19$.

Guzmán, Campos, Fals Borda, Orlando y Umaña LuNA, EDUARDO, La violencia en Colombia, Carlos Valencia editores, Bogotá 1986.

Hobsbawn, Eric, Trabajadores, Estudios de bistoria de la clase obrera, Edit. Crítica, Barcelona 1979. Política para una izquierda racional, Edit. Crítica, Barcelona 1993.

Instituto María CANO, Las organizaciones sociales y la constituyente, resumen de propuestas y comentarios, Bogotá, julio 1990. Participación y concertación social, los trabajadores y sectores populares en entidades de gobierno, Bogotá, septiembre 1990.

INURBE, La revolución pacífica, politica nacional de vivienda, Presidencia de la República, Ministerio de Desarrollo Económico, Bogotá 1992.

Lemoine, Carlos, Las fuerzas de la opinión, Centro Nacional de Consultoria, Bogotá 1993.

LONDOÑO, Rocío, Crisis y recomposición del sindicalismo colombiano (1946-1980), Nueva Historia de Colombia, Planeta, Bogotá 1989, t. III., "Al filo del Caos", Tercer Mundo-IEPRI, Bogotá 1989. Problemas laborales y reestructuración del sindicalismo. 
LÓPEZ, Hugo, Contexto macroeconómico colombiano, mercado laboral urbano y retos para una política de empleo, FESCOL, ponencia inédita, Medellín 1993.

LOSONCZY, ANNE MARIE, La organización social negrocolombiana del choco: unidades constitutivas y sistema social, documento inédito traducido al español por Adriana Maya, sin fecha.

Luna, Lola y Villarreal, Norma, Historia, genero y politica, movimiento de mujeres y participación política en Colombia 1930-1991, Universidad de Barcelona-Comisión Interministerial de Ciencia y Tecnología, Barcelona 1994.

Medina, Medófilo, La protesta urbana en Colombia, Ediciones Aurora, Bogotá 1984.

Ministerio de Trabajo y Seguridad Social, iII Censo Nacional Sindical, Boletín de análisis y estadísticas laborales, Bogotá, julio-diciembre 1989, N. ${ }^{\circ} 41$.

Mosquera, JuAN DE Dios, I Encuentro Nacional de organizaciones afrocolombianas, Cuaderno del Cimarrón 1992.

MOVIMIENTO CIMARRÓN, Listados de las organizaciones participantes en el primer y segundo encuentro de organizaciones afrocolombianas 1992-1993, Bogotá, archivo Mov. Cimarrón.

Murillo, Partor, Análisis comparativo del texto de la ley de 1993 resultante de la concertación entre el gobierno nacional y las comunidades negras, Revista "Esteros", $\sin$ fecha.

ONIC, Documento para la evaluación de la ONIC, Bogotá 1994. Desarrollo de la Constitución, agosto 1993. Acta IV Congreso Indigena Nacional, Natagaima, agosto 30 1993. Archivo ONIC, Bogotá.

PIZARRO, EdUARDO, Elecciones, partidos y nuevo marco institucional: ¿en qué estamos?, artículo en prensa, Revista “Análisis Político", Instituto de Estudios Políticos y Relaciones Internacionales, Universidad Nacional de Colombia, Bogotá 1994.

Potes, IsRael, Directorio Colombia 1994, Santafé de Bogotá, marzo 1994.

Restrepo, Luis Alberto, Potencial democrático de los movimientos, Corporación SOS Colombia, inédito, 1994.
Ríos, NorberTo, Efectos neoliberales en el sindicalismo, "Caja de Herramientas", Corporación SOS Colombia, Bogotá, agosto 1994, año 3, N. ${ }^{\circ} 20$.

SÁNCHEZ, ENRIQUe y OTROS, Derechos e identidad, los pueblos indígenas y negros en la constitución política de Colombia de 1991, Disloque editores, Santafé de Bogotá, 1993.

SÁnCHez, Gonzalo y PEÑARANDA, Ricardo, compiladores, Pasado y presente de la violencia en Colombia, CEREC, Bogotá 1986.

SAntana, Pedro, Los movimientos sociales en Colombia, Ediciones Foro Nacional por Colombia, Bogotá 1989.

TORres CARrillo, Alfonso, la ciudad en la sombra, CINEP, Bogotá 1993.

TORRES GIRALDO, IGNACIO, Los inconformes, Edit. Latina, Bogotá, sin fecha, tomos 3 y 4.

UNIVERSIDAD DEL VALLE y UNIVERSIDAD DE LOS ANDES, Proyecto de desarrollo de una metodología de evaluación de impacto y levantamiento de linea de base del programa integral campesino, PDIC, Informe final, Bogotá, agosto 1992.

Urrutia, Miguel, Historia del sindicalismo en Colombia, Universidad de los Andes, Bogotá 1969.

VÁsquez Toro, Magdala, Condición jurídica y Social de la mujer, Nueva Historia de Colombia, Planeta, Bogotá 1989, t. IV.

WADE, PETER, Lista de organizaciones comunitarias de gente negra en Colombia: Marzo 1993. Revista "America Negra”, Universidad Javeriana, Bogotá 1994, N. ‥ 5.

ZAMOSC, LEÓN, El campesinado y las perspectivas para la Democracia Rural, "Al filo del caos", Tercer MundoIEPRI, Bogotá 1990. Transformaciones agrarias y luchas campesinas en Colombia: un balance retrospectivo, Revista "Análisis Político", IEPRI, Universidad Nacional de Colombia, enero-abril 1992, N. ${ }^{\circ} 15$.

Zerda, Alvaro, Apertura, nuevas tecnologías y empleo, FESCOL, Bogotá 1992.

\section{RESUMEN}

El artículo examina el estado en que se encuentran las organizaciones populares y, en general, los actores sociales en Colombia y sus respuestas a la transformación del régimen político después de la Constitución de 1991, a la apertura económica, a la reducción del Estado y a la violencia política. Después de una breve retrospectiva, la autora se centra en los sindicatos y las experiencias de acción comunal, para ensayar finalmente una visión de futuro.

Palabras clave: Colombia, movimientos sociales, acción comunal, sindicatos, participación.

\section{ABSTRACT}

The article analyses the situation of popular organizations as well as the situation for the rest of Colombian social actors. It also focuses on answers of: the political transformation of the regime after the Constitution of 1991 , the economical opening process, the state reduction and to the political violence. After a brief retrospective, the author focuses the atention on the study of trade unions and comunitarian action experiences. And finally she gives us a kind of future perspective about all these questions.

Key words: Colombia, social movements, comunitarian action, trade unions, participation. 